Volume 9, No.1.4, 2020

International Journal of Advanced Trends in Computer Science and Engineering

Available Online at http://www.warse.org/IJATCSE/static/pdf/file/ijatcse8791.42020.pdf

https://doi.org/10.30534/ijatcse/2020/8791.42020

\title{
Performance Evaluation of Multi-Layer Perceptron (MLP) and Radial Basis Function (RBF): COVID-19 Spread and Death Contributing Factors
}

\author{
Shafaf Ibrahim ${ }^{1}$, Saadi Ahmad Kamaruddin², Nur Nabilah Abu Mangshor ${ }^{1}$, Ahmad Firdaus Ahmad \\ Fadzil $^{1}$ \\ ${ }^{1}$ Faculty of Computer and Mathematical Sciences, Universiti Teknologi MARA, Jasin, Melaka, Malaysia, \\ shafaf2429@uitm.edu.my, nurnabilah@uitm.edu.my, firdausfadzil@uitm.edu.my \\ ${ }^{2}$ School of Quantitative Sciences, College of Arts \& Sciences,Universiti Utara Malaysia,06010 UUM Sintok, \\ Kedah Darul Aman,Malaysia, saadiahmadkamaruddin@ gmail.com
}

\begin{abstract}
The Artificial Neural Network (ANN) is an Artificial Intelligence technique which has the ability to learn from experiences, enhancing its performance by adapting to the environmental changes. The key benefits of neural networks are the prospect of processing vast quantities of data effectively, and their ability to generalize outcomes. Considering the great potential of this technique, this paper aims to establish a performance evaluation of Multilayer Perceptron (MLP) and a Radial Basis Function (RBF) networks in investigating the contributing factors for COVID-19spread and death. The RBF and MLP networks are typically used in the same form of applications, however, their internal calculation structures are different. A comparison was made by using a dataset of COVID-19 cases in 41 Asia countries during April 2020. There are nine contributing factors which acted as the covariates to the network such as Cases, Deaths, High Temperature, Low Temperature, Population, Percentage of Cases over Population, and Percentage of Death over Population, Average Temperature, and Total Cases. The results obtained from the testing sets indicated that the two neural structures were able to investigate the COVID-19 spread and death contributing factors. Nevertheless, the RBFnetwork indicated a slightly better performance than the MLP.
\end{abstract}

Key words: COVID-19, Global Geographical Climate, Artificial Neural Network (ANN)

\section{INTRODUCTION}

COVID-19 has spread all over the world, locking up billions of people as health services struggle to cope [1]. Providentially, enormous global data distribution on COVID-19 is made available online with combination of global climate data, which creates an opening for further analysis to be conducted. This reflects the need for an analysis that is best suited to big data analysis which offers high performance and efficiency in understanding this pandemic issue.
The Artificial Neural Network (ANN) has the ability to learn from experiences, improving its performance and adapting to the changes in the environment [2]. The key benefits of neural networks are the prospect of processing vast quantities of data effectively, and their ability to generalize outcomes [3]. The ANNs are parallel distributed systems, consisting of simple processing units (artificial neurons) that measure with certain (usually nonlinear) [4] mathematical functions. These units are arranged in one or more layers and interconnected by a sufficient number of connections [5]. These connections are associated with weights in most models, which store the knowledge acquired by the model and are used to consider the input received by each neuron network[6].

The application of ANN to solve problems with fault diagnosis is of special interest due to its classification and practical approximation capabilities[7]. ANN approach is convenient when it is difficult to obtain an analytical model. There are numerous research conducted which using the ANN particularly on Multilayer Perceptron (MLP) and Radial Basis Function (RBF) such as and-written digit recognition [8], prediction of carbon dioxide solubility in ionic liquids [9], prediction of solution gas-oil ratio of crude oil systems [10], estimation of construction cost [11] and many more.

Considering the great potential of this technique, this paper aims to establish a comparison between a MLP and RBFin investigating the contributing factors for COVID-19 spread and death.The employment of the ANN is expected to contribute in understanding the contributing factors of the COVID-19 spread and death. The organization of the remainder of this paper is as follows: Section 2 elaborates the data background. Section 3 provides our methods, including an overview of the methodology, and the description of MLP and RBF structures. Our results and discussions are discussed in Section 4. Finally, in Section 5, we present our conclusion. 
Shafaf Ibrahim et al., International Journal of Advanced Trends in Computer Science and Engineering, 9(1.4), 2020, 625 - 631

Table 1: Descriptive Statistics

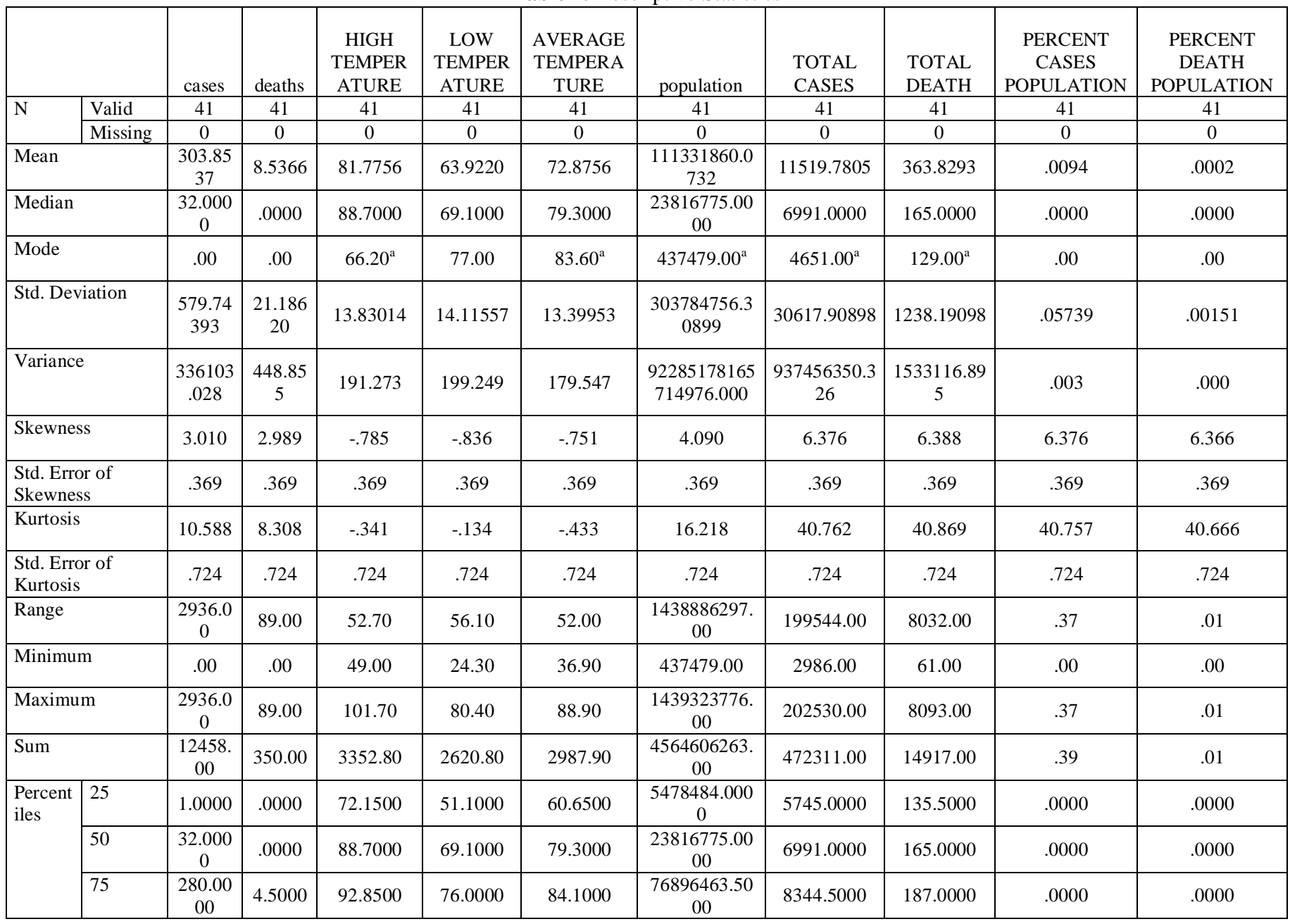

\section{DATA BACKGROUND}

A COVID-19 dataset which includes the number of cases and death were collected from the European Centre for Disease Prevention and Control(ECDPC), global geographical climate data were taken from the Weather Forecast, and population data is obtained from the Current World Population. The dataset covered the 41 countries in Asia, however, due to incomplete data distribution, three countries were excluded which are Palestine, Tajikistan and Yemen. The descriptive statistics data can be seen in Table 1.

\section{RESEARCH METHODS}

This paper aims to establish a performance evaluation of MLP and a RBF against spread and death contributing factors for COVID-19. The description of the MLP and RBF structures are explained further in the next subsections.

\subsection{Multilayer Perceptron (MLP) Network}

The MLP was applied to various fields, performing tasks such as behavioral analysis [12], solar forecasting [13], and body weigh estimation function fitting [14], using supervised training with an algorithm called "error back propagation.". A basic neuron with $\mathrm{R}$ inputs is shown in Figure 1.

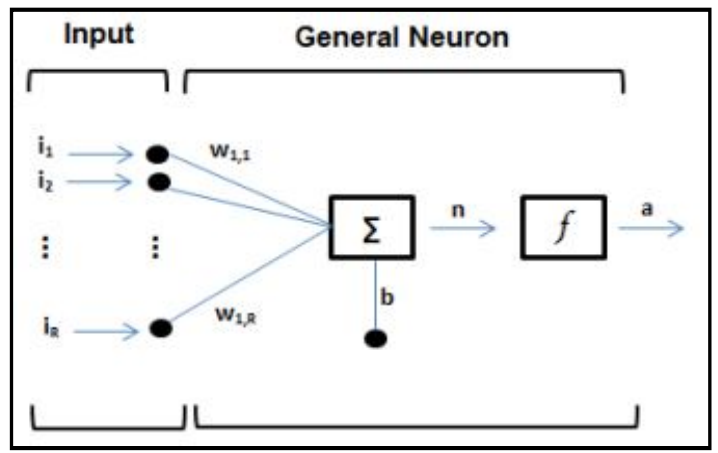

Figure 1: An elementary neuron with $\mathrm{R}$ inputs

Each input $(i)$ is weighted with an appropriate $w$. The weighted inputs sum and the bias form the input to the activation function $f$, and(1) represents the appropriate mathematical expression.

$a=f\left(w_{i}+b\right)$ 
where:

$a$ : output signal of the neuron

$w$ : weights between the neurons

$i$ : vector of input data

$b$ : bias added to the neurons where each neuron in the network includes an activation function $(f)$

The MLP also has one or more hidden layers of sigmoid neurons, accompanied by a linear neuronal output layer. The most significant nonlinear activation functions for MLP are the logarithmic and hyperbolic tangent functions. The command for linear activation function is purelin. The nonlinear activation function multiple layers of neurons enable the network to learn nonlinear relationships between input and output vectors.

\subsection{Radial Basis Function (RBF)Network}

The RBF network has the advantages such as easy design consisting of three-layer architecture, good generalization and high input noise tolerance and online learning capabilities. From the point of generalization, RBF networks can respond well to patterns that were not used for training [15]. The RBF neural network has an input, hidden and output layer. The input layer consists of an input vector I, as shown in Figure 2.

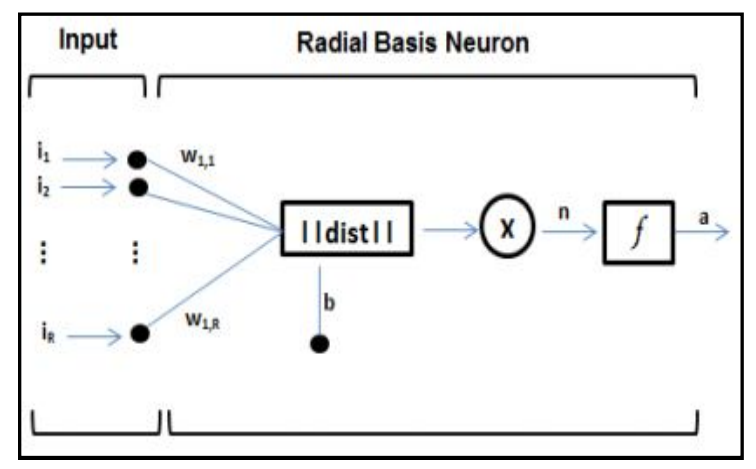

Figure 2:Radial basis network with $\mathrm{R}$ inputs

The networks neuron which is the RBF activation function is located in the hidden layer. The vector distance between its weight $(w)$ and the input vector $(i)$, multiplied by the bias $b$ is the net input to the RBF activation function. The mathematical expression of one artificial neuron of a radial basis function network is shown in (2).

$$
a=\operatorname{radbas}(\|w-i\| b)
$$

Radial functions are a special class of functions the value of which increases or decreases proportional to the distance from a central point.There are various types of radial basis functions, but the most commonly used is the Gaussian function. The command for using a RBF is radbas. The study in [16] claimed that the RBF networks are simpler than MLP networks. In spite of having more complex architectures, it is well known that the MLP networks have been applied successfully in several difficult problems. RBFs serve as local approximation networks and their outputs in certain local receptive fields are calculated by particular hidden units.
Oppositely, MLP networks run globally and all the neurons determine the network outputs.

\section{RESULTS}

The case processing summary for each MLP and RBF are presented in Table 2 and Table 3. In the preprocessing part, the data were dividedinto two sets which are training and testing. Based on the Table 2, the training set for MLP consist of $78 \%(32 / 41)$ of the overall data, while testingsets comprises of $21.95 \%(9 / 41)$ of the overalldata, $N=41$. There were no excluded values recorded.

Table 2: MLP Case Processing Summary

\begin{tabular}{|l|l|r|r|}
\hline \multicolumn{2}{|c|}{} & N & \multicolumn{1}{|c|}{ Percent } \\
\hline \multirow{2}{*}{ Sample } & Training & 32 & $78.0 \%$ \\
\cline { 2 - 4 } & Testing & 9 & $22.0 \%$ \\
\hline Valid & 41 & $100.0 \%$ \\
\hline Excluded & 0 & \\
\hline Total & 41 & \\
\hline
\end{tabular}

On the other hand, the training set for RBF consist of $73.2 \%$ (30/41) of the overall data, while testing sets comprises of $26.8 \%$ (11/41) of the overalldata, $\mathrm{N}=41$. There were no excluded values recorded as well as depicted in Table 3.

Table 3: RBF Case Processing Summary

\begin{tabular}{|l|l|r|r|}
\hline \multicolumn{2}{|c|}{} & N & \multicolumn{1}{c|}{ Percent } \\
\hline \multirow{2}{*}{ Sample } & Training & 30 & $73.2 \%$ \\
\cline { 2 - 4 } & Testing & 11 & $26.8 \%$ \\
\hline Valid & 41 & $100.0 \%$ \\
\hline Excluded & 0 & \\
\hline Total & 41 & \\
\hline
\end{tabular}

Subsequently, there are nine covariates used in the network which are Cases, Deaths, HighTemperature, Low Temperature, Population, Percentage ofCases over Population, and Percentage of Death overPopulation, Average Temperature, and Total Cases. Thesenine covariates were the inputs nodes in the input layer of the network. For the MLP, the network consists of only one hidden layer, withone single node. The activation function from input layer to hidden layer was Hyperbolic tangent. The target of the networkis COVID-19 spread and death, where the activation functionfrom hidden layer to output layer was identity (purelin). Thedefault error function in backpropagation neural network wasbased on sum of squares (SSE). To simplify, theconfigurations of this network was 9-1-1. The networkarchitecture for MLP can be referred in Figure 3. 


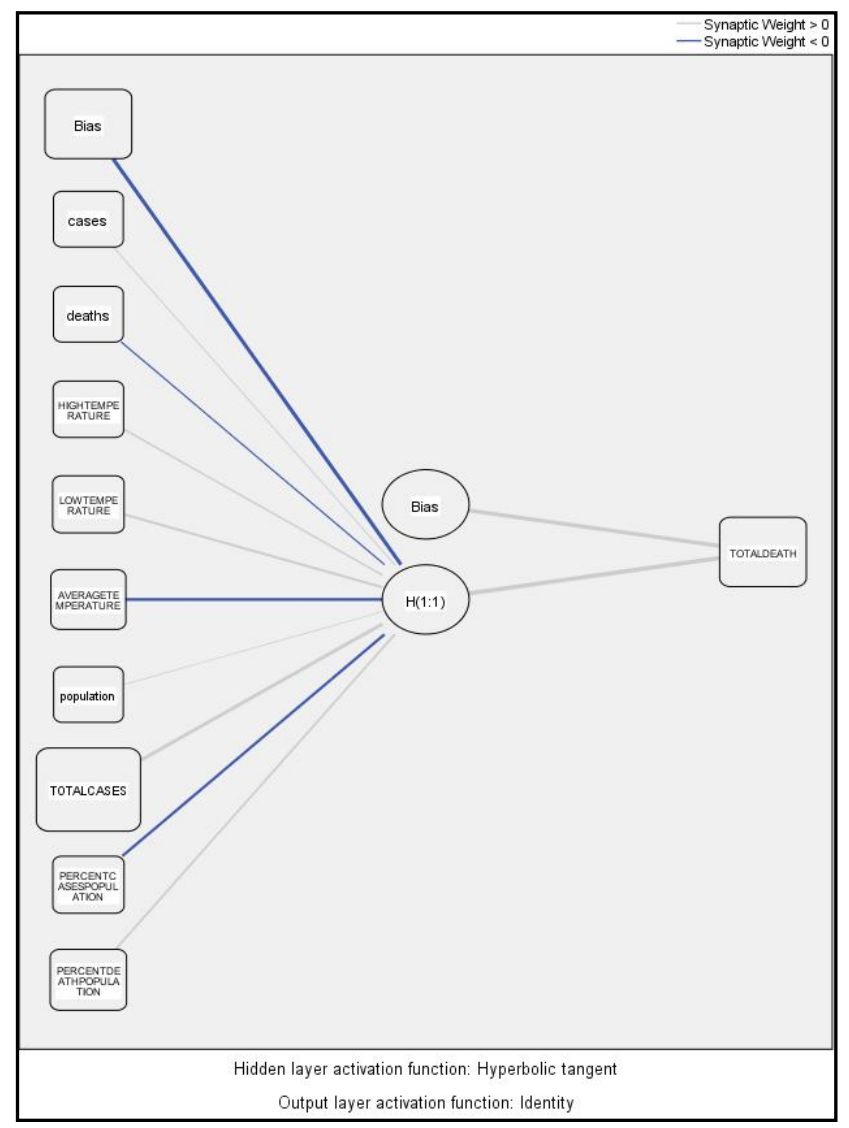

Figure 3: MLPNetwork Architecture

The RBF in contrast consists of seven hidden layers, withone seven nodes. The activation function from input layer tohidden layer was Softmax. Similar to the MLP, the target of the networkis COVID-19 spread and death, where the activation functionfrom hidden layer to output layer was identity (purelin). Thedefault error function in backpropagation neural network wasbased on sum of squares (SSE). To simplify, theconfigurations of this network was 9-7-1. The networkarchitecture for RBF is illustrated in Figure 4.

Next, Table 4 depicts the model summary of both training and testing sets for MLP and RBF networks. The Sum of Squares Error (SSE) for the MLP is 0.012 and 0.005 for $\mathrm{RBF}$ in the training set, with Relative Error (RE) equals to 0.001 and 0.000 for MLP and RBF respectively. Conversely, the SSE fortesting sets is 0.002 for MLP and 0.003 for RBF, with RE equals to 0.498 for MLP and 0.445 for RBF. Itcan be said that in any network, testing set should be the reference. The RE values for both MLP and RBF are monitored to be quite low. Therefore, it is firmly believed that both MLP and $\mathrm{RBF}$ networkperformances are in favorable structure.

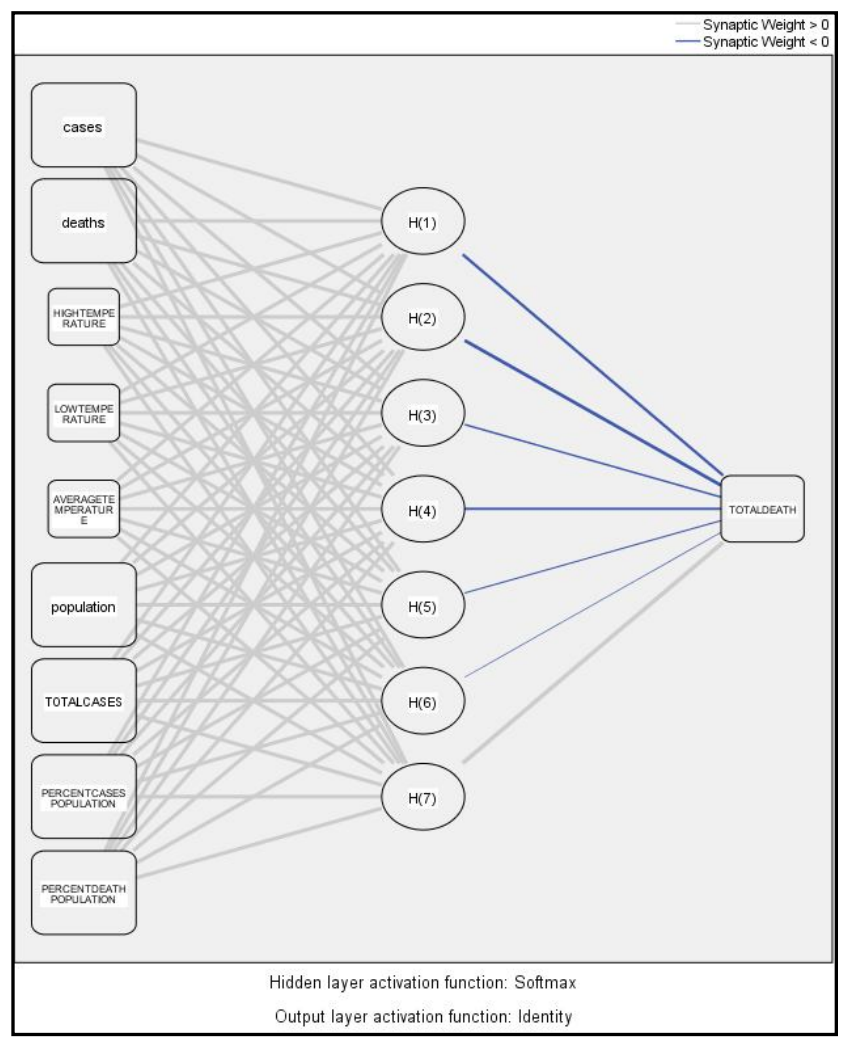

Figure 4: RBFNetwork Architecture

Table 4: MLP vs RBF Model Summary

\begin{tabular}{|c|c|c|c|}
\hline & & MLP & RBF \\
\hline \multirow{3}{*}{ Training } & $\begin{array}{l}\text { Sum of Squares } \\
\text { Error }\end{array}$ & .012 & .005 \\
\hline & Relative Error & .001 & .000 \\
\hline & Training Time & 0:00:00.00 & 0:00:00.09 \\
\hline \multirow[t]{2}{*}{ Testing } & $\begin{array}{l}\text { Sum of Squares } \\
\text { Error }\end{array}$ & .002 & $.003^{\mathrm{a}}$ \\
\hline & Relative Error & .498 & .445 \\
\hline
\end{tabular}

Dependent Variable: TOTALDEATH

a. The number of hidden units is determined by the testing data criterion: The "best" number of hidden units is the one that yields the smallest error in the testing data.

Table 5 and Table 6 display the independent variable importance for MLP and RBF networks accordingly. Referring to Table 6, the MLP network concluded that the top five most essential contributing factors towards COVID-19 spread and death are the Total cases $(100 \%)$, Percentage of death over population (19.9\%), Average temperature (15.8\%), Low temperature $(5.9 \%)$, and Percentage of cases over population $(5.4 \%)$. Whereas, the RBF network determined that the top six most importantcontributing factors towards COVID-19 spread and death are the Death (100\%), Cases (99.5\%), Population (99.2\%), and $99.1 \%$ for all Total cases, Percentage of cases over population, and Percentage of death over population. 
Shafaf Ibrahim et al., International Journal of Advanced Trends in Computer Science and Engineering, 9(1.4), 2020, 625 - 631

Table 5: MLP Independent Variable Importance

\begin{tabular}{|l|c|c|}
\hline & Importance & $\begin{array}{c}\text { Normalized } \\
\text { Importance }\end{array}$ \\
\hline cases & .008 & $1.2 \%$ \\
\hline deaths & .006 & $0.9 \%$ \\
\hline HIGHTEMPERATURE & .021 & $3.1 \%$ \\
\hline LOWTEMPERATURE & .038 & $5.9 \%$ \\
\hline AVERAGETEMPERATURE & .104 & $15.8 \%$ \\
\hline population & .003 & $0.5 \%$ \\
\hline TOTALCASES & .655 & $100.0 \%$ \\
\hline PERCENTCASESPOPULATION & .036 & $5.4 \%$ \\
\hline PERCENTDEATHPOPULATION & .131 & $19.9 \%$ \\
\hline
\end{tabular}

Table 6: RBF Independent Variable Importance

\begin{tabular}{|l|r|r|}
\hline & Importance & $\begin{array}{r}\text { Normalized } \\
\text { Importance }\end{array}$ \\
\hline cases & .149 & $99.5 \%$ \\
\hline deaths & .150 & $100.0 \%$ \\
\hline HIGHTEMPERATURE & .034 & $22.6 \%$ \\
\hline LOWTEMPERATURE & .036 & $23.9 \%$ \\
\hline AVERAGETEMPERATURE & .035 & $23.4 \%$ \\
\hline population & .149 & $99.2 \%$ \\
\hline TOTALCASES & .149 & $99.1 \%$ \\
\hline PERCENTCASESPOPULATION & .149 & $99.1 \%$ \\
\hline PERCENTDEATHPOPULATION & .149 & $99.1 \%$ \\
\hline
\end{tabular}

As previously discussed, the performance of the developed MLP and RBF networks were evaluated and investigated against a well-known empirical correlation using statistical and graphical error analyses which are SSE and RE.

By default, the rescaling method for covariates is Standardized. In this rescaling process, mean is subtracted from the values and the outcome is divided by the standard deviation. There are three more methods of rescaling which are Normalized, Adjusted normalized and None. Table 7, Table 8, Table 9 and Table 10 demonstrate the overall summary of RE and SSE for both MLP and RBF correspondingly (Figure 5).

Table 7: Relative Error of ANN MLP Models

\begin{tabular}{|l|c|c|}
\hline \multirow{2}{*}{\begin{tabular}{c}
\multirow{2}{*}{$\begin{array}{c}\text { Rescaling of } \\
\text { Covariates }\end{array}$} \\
\cline { 2 - 3 }
\end{tabular}} & $\begin{array}{c}\text { Scaled Conjugate } \\
\text { Gradient }\end{array}$ & Gradient Descent \\
\hline Standardized & 0.498 & 3.208 \\
\hline Normalized & 7.367 & 0.628 \\
\hline $\begin{array}{l}\text { Adjusted } \\
\text { Normalized }\end{array}$ & 0.923 & 1.575 \\
\hline None & 3.662 & 9.207 \\
\hline
\end{tabular}

Table 8: SSE of ANN MLP Models

\begin{tabular}{|l|c|c|}
\hline \multirow{2}{*}{\begin{tabular}{c}
\multirow{2}{*}{$\begin{array}{c}\text { Rescaling of } \\
\text { Covariates }\end{array}$} \\
\cline { 2 - 3 }
\end{tabular}} & $\begin{array}{c}\text { Scaled Conjugate } \\
\text { Gradient }\end{array}$ & Gradient Descent \\
\hline Standardized & 0.002 & 0.007 \\
\hline Normalized & 0.050 & 0.002 \\
\hline $\begin{array}{l}\text { Adjusted } \\
\text { Normalized }\end{array}$ & 0.002 & 0.004 \\
\hline None & 0.016 & 0.043 \\
\hline
\end{tabular}

Table 9: Relative Error of ANN RBF Models

\begin{tabular}{|l|c|c|}
\hline \multirow{2}{*}{$\begin{array}{c}\text { Rescaling of } \\
\text { Covariates }\end{array}$} & \multicolumn{2}{|c|}{$\begin{array}{c}\text { Radial Basis Neural Network Activation } \\
\text { Function for Hidden Layer }\end{array}$} \\
\cline { 2 - 3 } & $\begin{array}{c}\text { Normalized Radial } \\
\text { Basis Function }\end{array}$ & $\begin{array}{c}\text { Ordinary Radial } \\
\text { Basis Function }\end{array}$ \\
\hline Standardized & 1.169 & 0.971 \\
\hline Normalized & 0.445 & 0.677 \\
\hline $\begin{array}{l}\text { Adjusted } \\
\text { Normalized }\end{array}$ & 0.512 & 14458.309 \\
\hline None & 1.453 & 12281.433 \\
\hline
\end{tabular}

Table 10: SSE of ANN RBF Models

\begin{tabular}{|l|c|c|}
\hline \multirow{2}{*}{\begin{tabular}{c}
\multirow{2}{*}{$\begin{array}{c}\text { Rescaling of } \\
\text { Covariates }\end{array}$} \\
\cline { 2 - 3 }
\end{tabular}} & $\begin{array}{c}|c| \\
\text { Radial Basis Neural Network Activation } \\
\text { Function for Hidden Layer }\end{array}$ \\
\hline Standardized & 0.005 & 0.010 \\
\hline Normalized & 0.003 & 0.003 \\
\hline $\begin{array}{l}\text { Adjusted } \\
\text { Normalized }\end{array}$ & 0.005 & 1.050 \\
\hline None & 0.008 & 1.164 \\
\hline
\end{tabular}

Based on the Table 7 and 8, it can be monitored that MLP produced the best result in Standardized rescaling method, in which it returned the lowest values of SSE and RE of 0.498 and 0.002 as compared to the Normalized, Adjusted Normalized, and None.

Table 11: Configurations of ANN MLP Models

\begin{tabular}{|l|c|c|}
\hline \multirow{2}{*}{\begin{tabular}{c}
\multirow{2}{*}{$\begin{array}{c}\text { Rescaling of } \\
\text { Covariates }\end{array}$} \\
\cline { 2 - 3 }
\end{tabular}} & $\begin{array}{c}\text { Scaled Conjugate } \\
\text { Gradient }\end{array}$ & Gradient Descent \\
\hline Standardized & $9-1-1$ & $9-1-1$ \\
\hline Normalized & $9-1-1$ & $9-1-1$ \\
\hline $\begin{array}{l}\text { Adjusted } \\
\text { Normalized }\end{array}$ & $9-1-1$ & $9-1-1$ \\
\hline None & $9-1-1$ & $9-1-1$ \\
\hline
\end{tabular}

Table 12: Configurations of ANN RBF Models

\begin{tabular}{|c|c|c|}
\hline \multirow{2}{*}{$\begin{array}{l}\text { Rescaling of } \\
\text { Covariates }\end{array}$} & \multicolumn{2}{|c|}{$\begin{array}{c}\text { Radial Basis Neural Network Activation } \\
\text { Function for Hidden Layer }\end{array}$} \\
\hline & $\begin{array}{l}\text { Normalized Radial } \\
\text { Basis Function }\end{array}$ & $\begin{array}{l}\text { Ordinary Radial } \\
\text { Basis Function }\end{array}$ \\
\hline Standardized & $9-10-1$ & $9-8-1$ \\
\hline Normalized & $9-7-1$ & $9-3-1$ \\
\hline $\begin{array}{l}\text { Adjusted } \\
\text { Normalized }\end{array}$ & $9-7-1$ & $9-5-1$ \\
\hline None & $9-4-1$ & $9-10-1$ \\
\hline
\end{tabular}




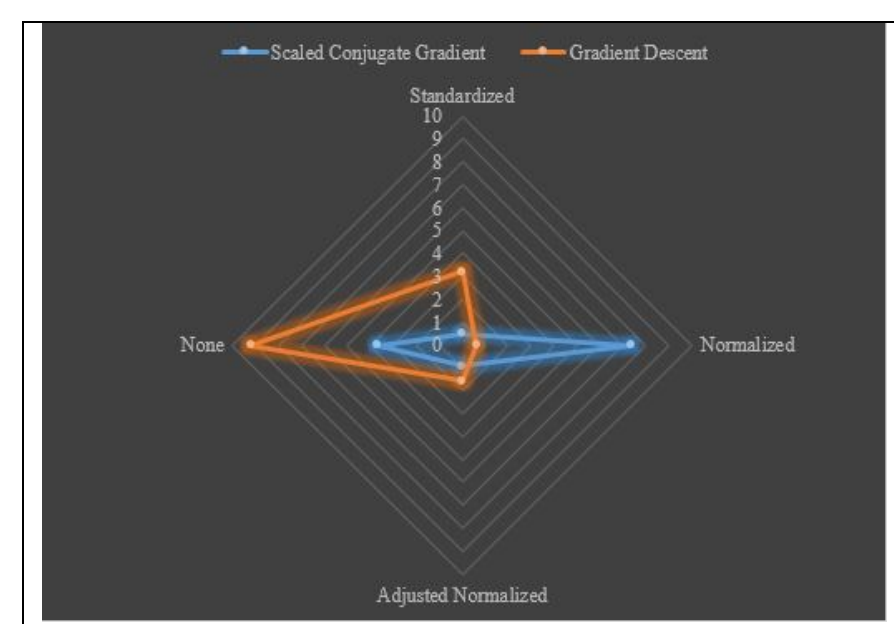

Relative Error of ANN MLP Models

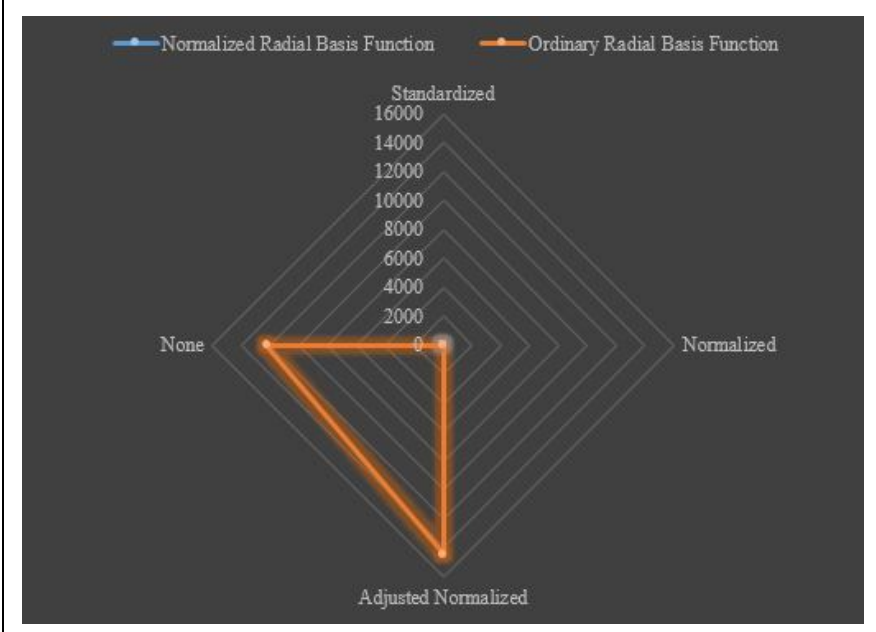

Relative Error of ANN RBF Models

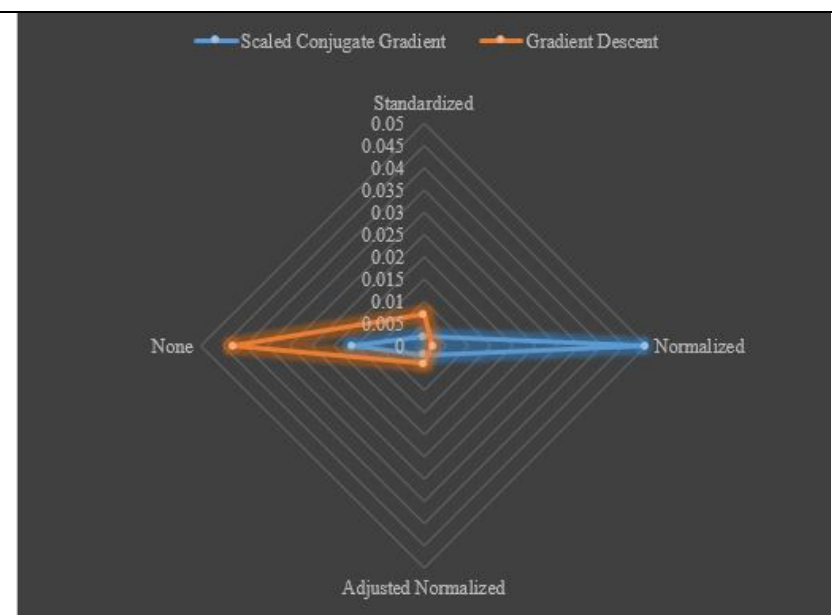

SSE of ANN MLP Models

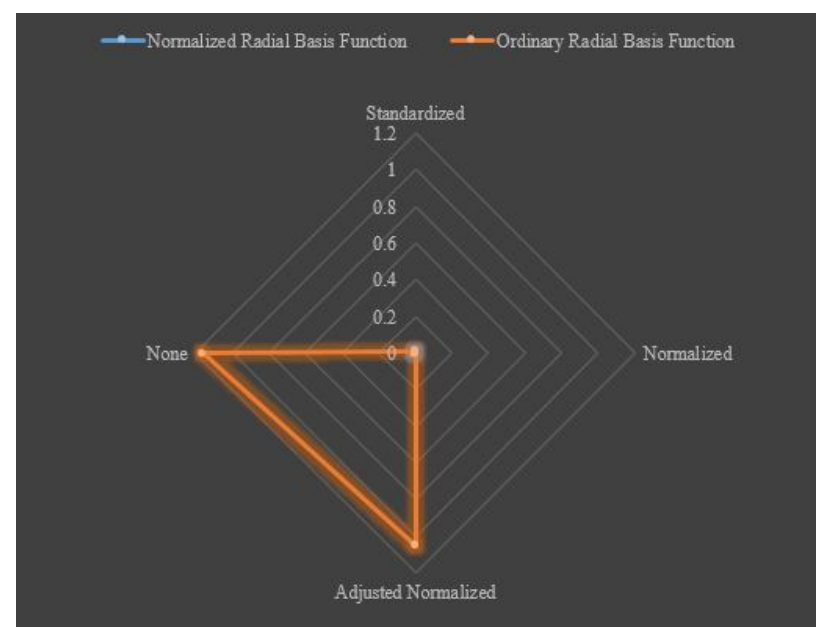

SSE of ANN RBF Models

Figure 5: Overall summary of RE and SSE for both MLP and RBF models

Alternatively, the RBF is seen to compute the lowest RE and SSE values in the Normalized rescaling method which are 0.445 and 0.003 , and are found to produce lower error rates than the MLP network as shown in Table 9 and Table 10. All configurations of both techniques can be referred in Table 11 and Table 12.

Conclusively, the performance evaluation indicated that both ANN models of MLP and RBF are effective in investigating the contributing factors of COVID-19 spread and death. However, the developed RBF exhibited higher accuracy and efficiency as compared to the proposed MLP model.

\section{CONCLUSION}

This paper presents a study on performance evaluation of Multilayer Perceptron (MLP) and a Radial Basis Function (RBF) networks in investigating the contributing factors for COVID-19 spread and death.A comparison was made by using a dataset of COVID-19 cases in 41 Asia countries during April 2020. There are nine contributing factors which acted as the covariates to the network such as Cases, Deaths,
High Temperature, Low Temperature, Population, Percentage of Cases over Population, and Percentage of Death over Population, Average Temperature, and Total Cases.The performance evaluation indicated that both ANN models of MLP and RBF are effective in investigating the contributing factors of COVID-19 spread and death. However, the developed RBF indicated a slightly better performance than the MLP.

\section{ACKNOWLEDGMENT}

The research was supported by Universiti Teknologi MARA Cawangan Melaka through the Teja Internal Grant 2020 (GDT2020-19).

\section{REFERENCES}

1. G. D. Rubin, C. J. Ryerson, L. B. Haramati, N. Sverzellati, J. P. Kanne, S. R. N. Raoof, N. W. Schluger, A. Volpi, J. Yim, I. B.K. Martin, D. J. Anderson, C. Kong, T. Altes, A. Bush, S. R. Desai, J. Goldin, J. M. Goo, M. Humbert, Y. Inoue, H. Kauczor, F. Luo, P. J. 
Mazzone, M. Prokop, M. Remy-Jardin, L. Richeldi, C. M. Schaefer-Prokop, N. Tomiyama, A. U. Wells, and A. N. Leung. The Role of Chest Imaging in Patient Management During the COVID-19 Pandemic: A Multinational Consensus Statement From the Fleischner Society, Radiology, vol. 296, no. 1, pp. 106-116, 2020.

2. R. Yang, R. Xiong, S. Ma, and X. Lin.Characterization of external short circuit faults in electric vehicle Li-ion battery packs and prediction using artificial neural networks, Applied Energy, Vol. 260, pp. 114-253, 2020. https://doi.org/10.1016/j.apenergy.2019.114253

3. K. Venu, P. Natesan, B. Krishnakumar, and N. Sasipriyaa.Disease Identification in Plant Leaf Using Deep Convolutional Neural Networks, inHandbook of Research on Applications and Implementations of Machine Learning Techniques, B. Patil and M. Vohra, India: IGI Global, 2020, ch. 3, pp. 46-62.

4. M. Tawarish andK. Satyanarayana.A Review on Pricing Prediction on Stock Market by Different Techniques in the Field of Data Mining and Genetic Algorithm, International Journal of Advanced Trends in Computer Science and Engineering, vol. 8, no. 1, pp. 23-26, 2019. https://doi.org/10.30534/ijatcse/2019/05812019

5. A. D. M. Africa, F. X. Asuncion, J. L. Tiberio, and R. M. F. A. Munchua.Sensor-based Traffic Control Network with Neural Network Based Control System, International Journal of Advanced Trends in Computer Science and Engineering, vol. 8, no. 4, pp. 983-989, 2019.

https://doi.org/10.30534/ijatcse/2019/01842019

6. I. Kononenko and M. Kukar.Chapter 11 - Artificial Neural Networks, in Machine Learning and Data Mining, I. Kononenko, M. Kukar, Woodhead Publishing, 2007, pp. 275-320.

7. I. Barradas, L. E. Garza, and R. M. Menendez.Leak Detection in a Pipeline Using Artificial Neural Networks, in $14^{\text {th }}$ Iberoamerican Congress on Pattern Recognition Image Analysis, Computer Vision, and Applications, Cuba, 2009, pp. 637-644.

8. A. Musa and F. Aliyu.Performance Evaluation of Multi-Layer Perceptron (MLP) and Radial Basis Function (RBF),2019 2nd International Conference of the IEEE Nigeria Computer Chapter (NigeriaComputConf), Nigeria, 2019, pp. 1-5.

9. A. Tatar, S. Naseri, M. Bahadori, A. Z. Hezave, T. Kashiwao, A. Bahadori, and H. Darvish.Prediction of carbon dioxide solubility in ionic liquids using MLP and radial basis function (RBF) neural networks, Journal of the Taiwan Institute of Chemical Engineers, Vol. 60, pp. 151-164, 2016.

10. A. H. Fath, F. Madanifar, and M. Abbasi.Implementation of multilayer perceptron (MLP) and radial basis function (RBF) neural networks to predict solution gas-oil ratio of crude oil systems, Petroleum, volume 6, issue 1, pp. 80-91, 2020.

11. S. Bayram, M. E. Ocal, E. L. Oral, and D. Atis.Comparison of multi layer perceptron (MLP) and radial basis function (RBF) for construction cost estimation: the case of Turkey, Journal of Civil Engineering and Management, vol. 22, no. 4, pp. 480-490, 2016. https://doi.org/10.3846/13923730.2014.897988

12. K. Hambarde, G. Silahtaroğlu, S. Khamitkar, P. Bhalchandra, H. Shaikh, P. Tamsekar, and G. Kulkarni. Augmentation of Behavioral Analysis Framework for E-Commerce Customers Using MLP-Based ANN, inAdvances in Data Science and Management. Lecture Notes on Data Engineering and Communications Technologies, Borah S., Emilia Balas V., and Z. Polkowski, Singapore: Springer, 2020, pp. 45-50.

13. G. M. Paiva, S. P. Pimentel, P. B. Alvarenga, G. E. Marra, M. E. Mussetta, and L. S. Leva. Multiple Site Intraday Solar Irradiance Forecasting by Machine Learning Algorithms: MGGP and MLP Neural Networks. Energies 2020, vol. 13, no. 3005, pp. 1-28, 2020.

14. L. Sangün, O. Güney, P. Özalp, and N. Başusta. Estimation of body weight of Sparus aurata with artificial neural network (MLP) and M5P (nonlinear regression)-LR algorithms. Iranian Journal of Fisheries Sciences, vol. 19, no. 2, pp. 541-550, 2020.

15. R. B. Santos, M. Rupp,S. J. Bonzi, and A. M. F. Fileti. Comparison between multilayer feedforward neural networks and a radial basis function network to detect and locate leaks in pipelines transporting gas. Chemical Engineering Transactions, Vol. 32, pp. 1375-1380, 2013.

16. H. Yu, T. Xie, S. Paszezynski, and B. M. Wilamowski. Advantages of Radial Basis Function Networks for Dynamics System Design, IEEE Transactions on Industrial Electronics, vol. 58, no. 12, pp. 5438-5450, 2011. 